\title{
Guiné-Bissau e Cabo Verde: identidades e nacionalidades em construção
}

Daniele Ellery Mourão *

Resumo: $\mathrm{O}$ artigo apresenta uma reflexão sobre os processos de ressignificação de identidades e nacionalidades a partir dos resultados da pesquisa (Ellery Mourão, 2006) realizada com estudantes guineenses e cabo-verdianos formados no Brasil. Aborda a construção das identidades em Cabo Verde e em Guiné-Bissau a partir das concepçōes dos sujeitos pesquisados. $\mathrm{Na}$ pesquisa foram constatados distintos processos de construção de identidades: cultural (étnica) e nacional nesses países, o que possibilitou a estes a adoção de diferentes estratégias de inserção no "modelo democrático" do Estado-Nação. O artigo versa sobre as identidades guineenses e cabo-verdianas e seus específicos processos de construção de nacionalidades, tendo como foco central a importância da formação dos estudantes no Brasil para a ressignificação de suas identidades nacionais. A pretensão é desconstruir idéias correntes sobre o continente africano — como um todo homogêneo — , bem como sobre nação e nacionalidade postas pelo Ocidente, considerando as intençôes políticas e econômicas universalistas subjacentes a essas idéias.

Palavras-chave: identidades; nacionalidades; educação superior.

Guinea Bissau and Cape Verde: identities and nationalities in construction

Abstract: This article presents a reflection on the process of resignification of identities and nationalities from the results of Ellery Mourão's research (2006) done with students from Cape Verde and Guinea Bissau, graduated in Brazilian universities. It focuses on the construction of identities in those countries from the conceptions of the subjects interviewed. Different identitys construction processes were found: a cultural (ethnic) one in Caper Verde and a national one in Guinea Bissau. Such a difference allowed the adoption of different strategies in the insertion on the nation-State democratic model. The article is about Guinean and Capeverdian identities and their specific nationality construction processes, focusing on the importance of studying in Brazil for students to resignify their national identities. The intention is to deconstruct current ideas about the African continent as a whole, as well as the notions of nation and nationality imposed by the Western world, considering the political and economical intentions underlying these ideas.

Key words: identities; nationalities; higher education.

* Departamento de Pós-Graduação em Sociologia, Universidade Federal do Ceará, Fortaleza, Ceará, Brasil. daniellery30@yahoo.com.br 
O presente artigo pretende refletir sobre processos de construção de identidades e nacionalidades a partir da pesquisa de Ellery Mourão (2006) com estudantes guineenses e cabo-verdianos formados no Brasil ${ }^{1}$. Por meio da análise de depoimentos de 27 estudantes formados em universidades brasileiras, hoje profissionais influentes em seus países de origem, a pesquisa mostrou como vem ocorrendo o processo nunca acabado e multifacetário de construção das nacionalidades e de consolidação do Estado nacional guineense e caboverdiano. A premissa é que a experiência de vida no Brasil, durante a formação acadêmica dos sujeitos pesquisados, tenha possibilitado processos de ressignificação ${ }^{2}$ de suas identidades e nacionalidades. $\mathrm{O}$ trabalho de campo foi realizado no período de 2004 a 2006, inicialmente em Fortaleza (Brasil) com os estudantes que ainda estavam com seus cursos universitários em andamento; posteriormente, em Praia (Ilha de Santiago/Cabo Verde) ${ }^{3}$ e em Bissau (Guiné-Bissau), com os estudantes egressos, inseridos no mercado de trabalho em seus países.

A partir das entrevistas foram constatados distintos processos de construção de identidades - cultural (étnica) e nacional - e de inserção no "modelo democrático" ocidental de Estado-Nação. Isso possibilitou perceber as identidades específicas guineenses e cabo-verdianas e os diferentes processos de construção das nacionalidades em ambos os países, questionando a idéia do continente africano como um todo homogêneo e de nação e nacionalidade posta pelo Ocidente, bem como as intençôes políticas e econômicas - construídas socialmente por determinados grupos com interesses estratégicos — subjacentes a essa idéia.

Para explorar analiticamente a problemática empírica acima citada, inspirei-me no conceito de identidade formulado por Carneiro da Cunha (1986), como uma estratégia de diferença, numa perspectiva relacional, situacional e de manipulação das próprias diferenças. Identidade(s) aqui se refere às múltiplas identidades dos sujeitos, à maneira como nos vemos e somos vistos, como nos

I. Os estudantes integram o Programa de Estudantes Convênio-Graduação (PEC-G), uma política de cooperação entre o Brasil e países considerados pelo programa em "vias de desenvolvimento", especialmente aqueles do continente africano e da América Latina.

2. "Ressignificação" está aqui sendo referido no sentido dado por Sahlins (1990), que aborda os processos de mudanças como ancorados em esquemas culturais preexistentes, mas que podem incorporar novos elementos de forma a fazer sentido numa nova situação, sendo, portanto, ressignificados,

3. Cabo Verde é um país formado por dois conjuntos de ilhas agrupados pela sua posição em relação aos ventos predominantes: o de Barlavento (Santo Antão, São Vicente, Santa Luzia, São Nicolau, Sal, Boa Vista e os ilhéus de Branco e Raso) e o de Sotavento (Maio, Santiago, Fogo, Brava e os ilhéus Secos ou Rombo). Na llha de Santiago, local em que foi realizada a pesquisa de mestrado, está situada a capital do país, Praia. 
identificamos e nos identificam. Numa referência a Hall (2003), identidades não essencializadas, não fixas e não homogêneas, mas sim permeáveis e fluidas. Chamo a atenção para a questão da identidade cultural que, no sentido de Todorov (1999), não se limita às identidades nacionais; incluem-se outras, ligadas aos grupos pela idade, pelo sexo, pela profissão, pelo meio social e. por isso, também consideradas situacionais. Já a referência à identidade nacional consiste numa abordagem como a tratada por Anderson (1989), que privilegia o sentimento de pertença a uma nação, constituído por meio de simbologias, sistemas de valores, crenças e ideologias criadas para dar unidade à identidade coletiva. Isso sem perder de vista que toda afirmação de identidade nacional é situada histórica e estrategicamente, dependendo da situação vivida pelos indivíduos. Nesse sentido, também o conceito de nação, marcado historicamente por idéias sintetizadoras, pretende aqui ser pensado de forma múltipla e plural, considerando-o não restrito exclusivamente à língua, ao território, à religião ou à raça, embora todos esses referenciais sejam construtores de identidade nacional (Hall, 2003).

\section{Cabo Verde e Guiné-Bissau: uma história entrelaçada pela colonização}

Guiné-Bissau e Cabo Verde são muito próximos geograficamente, têm histórias de lutas políticas comuns, entrelaçadas pela colonização, mas com uma constituição identitária bastante diversa. Cabo Verde era um conjunto de ilhas inabitadas antes da chegada dos portugueses no século $\mathrm{XV}^{4}$. Para lá foram levados os escravos, indivíduos do continente africano, especialmente guineenses, que seriam comercializados na Europa e posteriormente nas Américas. Nas ilhas cabo-verdianas houve um intenso processo de miscigenação entre colonizadores - especialmente portugueses - e africanos de diversos países do continente - privilegiadamente de guineenses, pela proximidade geográfica. Forçadamente, uns deram origem a outros, e, segundo o historiador cabo-

4. Em < caboverde.vozdipovo-online.com/historia/.../cabo-verde:-do-seu-achamento-a-independencianacional/> lê-se: "Admite-se, de modo geral, que as ilhas tenham sido encontradas pelos portugueses durante duas viagens sucessivas entre 1460 e 1462. Essas datas são conhecidas através dos seguintes documentos: $\bigcirc$ diploma de três de Dezembro de 1460 (vinte dias após a morte do Infante D. Henrique) que apenas faz referência às cinco primeiras do grupo ocidental: Sam Jacob (Santiago), Sam Filipe (Fogo), De las Mayes (Maio), Sam Christovam (Boa vista) e Lana (Sal) que D. Afonso V doou a seu irmão D. Fernando. A Carta de doação de 19 de Setembro de 1462 que se refere às cinco acima mencionadas, às cinco restantes e a dois ilhéus: ilha Brava, ilha de Sam Nicolau, ilha de Sam Vicente, ilha Rasa (ilhéu Raso), ilha Branca (ilhéu Branco), ilha de Santa Luzia e a ilha de Sant'Antonio (Santo Antão). Admite-se, igualmente, que as cinco primeiras tenham sido encontradas ainda em vida do Infante D. Henrique, pois o diploma a que acima nos referimos as transfere para o Infante D. Fernando do mesmo modo que as tinha recebido aquele infante". 
verdiano Correa e Silva (2004), o resultado desta "união" em Cabo Verde produziu algo totalmente novo: o povo cabo-verdiano. Assim, poderíamos considerar que Cabo Verde é produto do período colonial.

Segundo Appiah (1997), para compreender a variedade das tradiçóes culturais na África contemporânea, é preciso não apenas observar as diferentes experiências coloniais que elas vivenciaram, mas, antes de tudo, olhar para as culturas pré-coloniais. Para o autor, até mesmo políticas coloniais idênticas, igualmente implementadas sobre materiais culturais diferentes, produziram resultados extremamente variados. É nesse sentido que Thomaz (2002) diz que o saber e o poder colonial português, "produto e produtor de uma mentalidade colonial", constituíram distintas realidades, na medida em que os projetos de colonização eram diferentes nas diversas colônias: "As fronteiras do império se definiam e passavam a incorporar, de forma diferenciada, nativos da África, Ásia e Oceania" (Thomaz, 2002, p.21). Segundo o autor, noções como assimilation, concebida pelos franceses e indirect rule, pelos britânicos, referiam-se às diversas maneiras de tratar e conceber a idéia de diversidade cultural $\mathrm{e}$ às várias possibilidades de os indígenas poderem ser ou não emancipados e incorporados. $\mathrm{O}$ processo não foi unívoco, e não podemos deixar de mencionar toda a violência e a exploração colonial.

No que se refere a Cabo Verde e a Guiné-Bissau, países dos sujeitos pesquisados, essa é uma questão importante, uma vez que tiveram o mesmo colonizador, mas políticas coloniais diversas. O regime de Salazar, ao estabelecerse, anunciava a necessidade de trazer as populaçóes indígenas para a civilização e para a nação portuguesa (Vale de Almeida, 2004a), proclamando a "assimilação". No entanto, nem todos foram incorporados e nem da mesma forma. Cabo Verde foi visto como extensão de Portugal. Segundo Vale de Almeida, na África continental houve uma distinção real, embora nem sempre legal, entre os colonos brancos (portugueses), os intermediários "assimilados" (caboverdianos e são-tomenses) e os indígenas "não civilizados" (guineenses, angolanos, moçambicanos). Os cabo-verdianos, em especial as elites locais, encontravam-se numa situação in-between, "entre" um e outro: oficialmente não eram considerados indígenas e, sim, cidadãos portugueses, porém não da mesma forma que os portugueses.

Hernandez (2002) ressalta que foi em razão das condições geoeconômicas do arquipélago que se tornou possível, em Cabo Verde, a criação de um espaço administrativo onde funcionavam escolas, ainda que precárias, fornecendo mãode-obra qualificada para as demais colônias. Segundo a autora, isso contribuiu para a formação de indivíduos aptos e ideologicamente confiáveis e, por isso, os escolhidos pela metrópole como um elo de transmissão da administração colonial, criando em Angola, Moçambique e, em particular, na Guiné Portuguesa, 
rivalidades por parte dos nativos com os cabo-verdianos (Hernandez, 2001, p.103). Seguindo a linha de pensamento de Hernandez, Vale de Almeida (2004b) mostra que a lei orgânica do Ultramar Português, de 1953, que substituiu a carta orgânica de 1933, mudou a tônica da política colonial, voltandose para a idéia de "assimilação". E em 1954 o Estatuto dos Indígenas das Províncias da Guiné, Angola e Moçambique iria definir que os indivíduos nascidos nesses países e que ali viviam, desde então, não possuíam educação, hábitos pessoais e sociais julgados pela metrópole necessários para a aplicação integral do direito público e privado dos cidadãos portugueses 5 . No entanto, dessa classificação e da política de incorporação dos nativos, os cabo-verdianos foram excluídos; desde o liberalismo têm sido classificados como portugueses. E, segundo Vale de Almeida: "As elites locais jogarão mesmo importante papel intermediador nas estruturas administrativas em outras colônias portuguesas" (Vale de Almeida, 2004b, p.261).

Isso fez com que essas identidades em contato contínuo, no período colonial, fossem sendo construídas umas em oposição às outras, gerando distinções e rivalidades entre os indivíduos (Hernandez, 2002). No entanto, dependendo da situação, essas oposições identitárias podiam ser amenizadas ou acentuadas ${ }^{6}$. Em relação a cabo-verdianos e guineenses, as distinções foram amenizadas em função das lutas conjuntas por independência, o que não indicava ausência de conflitos. No caso dos cabo-verdianos e portugueses, as diferenças podiam ser suavizadas quando, estrategicamente, os cabo-verdianos identificavam-se também como europeus, "atlânticos" - em razão de sua posição geográfica privilegiada como ilha, entre o continente africano e o europeu - vendo em Portugal uma porta para a Europa; ou quando os próprios portugueses se voltavam para os cabo-verdianos como uma entrada para a África. Essas distinções criadas no período colonial hoje são traduzidas em ressentimentos, mesmo em situação de diáspora. Isso foi observado por mim, tanto nas entrevistas como também em conversas informais com estudantes guineenses, cabo-verdianos e angolanos, em Fortaleza.

Para tornarem-se independentes de Portugal, liderados por Amilcar Cabral, - um guineense filho de cabo-verdianos - cabo-verdianos e guineenses idealizaram estrategicamente a constituição de um estado binacional, englobando Guiné-Bissau e Cabo Verde (Koudawo, 2001). Por algum tempo, tiveram o mesmo partido - Partido para a Independência de Guiné-Bissau e Cabo Verde (PAIGC) - e o mesmo hino nacional. A favor da união, atenuaram diferenças

5. Castelo (1999, p.60) apud Vale de Almeida (2004b, p.26I).

6. Evans-Pritchard (1978) em seu estudo sobre os Nuers mostrou que os movimentos de fusão e fissão levavam os grupos ora a se unirem ora a se oporem, a depender da situação e das relações que eram estabelecidas em função de algum acontecimento. 
entre etnias, religiões, tradições culturais, valores e crenças. Mas as divergências e distinçôes prevaleceriam à união, separando definitivamente os indivíduos e seus países após a independência, em razão de conflitos entre suas elites no poder.

Como definiu Geertz (2000), o pertencimento a uma nação refere-se ao sentimento de identidade e identificação com aqueles de quem se descende, com quem se parece no pensar, na aparência, na maneira de falar, de comer, de rezar, de gesticular e a quem se está empaticamente ligado, haja o que houver. Mas, se por um lado, Geertz ressalta o caráter unificador dado pelo pertencer a uma nação, por outro, afirma que "Quanto mais as coisas se juntam, mais ficam separadas...” (Geertz, 2000, p.217). A questão é que muitos indivíduos de "naçôes" diferentes e/ou etnias diferentes, com tradições culturais distintas foram colocados, no período colonial, em contínuo contato dentro de um mesmo território, pondo em evidência diferenças e produzindo desigualdades e relações de poder. Isso derivou na emergência de diversos conflitos, como ocorrido entre guineenses e cabo-verdianos.

\section{A formação superior e a construção das jovens nações na África}

Segundo os sujeitos da pesquisa, a formação acadêmica sempre foi vista como algo imprescindível para a construção das jovens naçôes ${ }^{7}$. Com a independência de Guiné-Bissau (1974) e de Cabo Verde (1975), os países passaram a estabelecer mais amplamente os convênios de graduação - com a antiga União Soviética, Cuba, Portugal, Estados Unidos e também com o Brasil; mas, mesmo após a independência, a preferência dos estudantes guineenses e caboverdianos era fazer a formação superior em Portugal. O fator que contribuía fortemente para isso, além de Portugal exercer forte influência como antiga metrópole, era que o país abrigava e ainda abriga uma grande população de imigrantes de países da África de língua portuguesa ${ }^{8}$, como cabo-verdianos, guineenses, angolanos, moçambicanos, são-tomenses. Por meio de grandes redes de relaçôes ${ }^{9}$ os estudantes podiam contar com a ajuda de familiares e ami-

7. Alguns relatos dos sujeitos em Ellery Mourão (2006) expressaram nitidamente um sentimento de compromisso para a construção da nação como algo "natural" (termo nativo), definido a priori e naturalizado entre as pessoas. Uma das entrevistadas cabo-verdianas disse que desde criança sempre soube que um dia tinha que sair para estudar fora. Outro estudante (guineense) relatou: "tenho que formar pra voltar lá, porque o país precisa de mim". Esse sentimento, construído socialmente, incorpora os discursos nacionalistas.

8. Ver Gusmão (2005).

9. Ver Barnes (1987) que, na Antropologia, adotou o conceito de rede de relações (social networks), como relações interpessoais concretas que surgem a partir da afiliação a um grupo, vinculando indivíduo a indivíduo por laços de parentesco ou de amizade - relação de troca e de reciprocidade.

Pro-Posiçōes, Campinas, v. 20, n. 1 (58), p. 83-101, jan./abr. 2009 
gos em Portugal, o que representava apoio para moradia, para estabelecerem-se melhor financeiramente, além de poderem partilhar de grande suporte emocional na nova situação vivida como estrangeiros. Outro ponto importante na opção por Portugal, segundo relatos (Ellery Mourão, 2006), é que o mercado de trabalho em Guiné-Bissau, e mais ainda em Cabo Verde, dava preferência ao estudante que vinha formado pelas universidades portuguesas. Os pais dos estudantes faziam grande objeção a enviar seus filhos para o Brasil, pois havia uma crença de que o Brasil era um país de "farra", muito informal, e que o brasileiro "tropeçava na língua portuguesa", sendo o português de Portugal considerado "o verdadeiro português". Com isso, os estudantes formados no Brasil, notadamente entre os anos 1970 e 1980, quando regressavam ao seu país de origem, encontravam dificuldades de inclusão no mercado de trabalho. A partir de finais da década de 1980, ocorreram mudanças nesse processo, havendo uma maior procura entre os estudantes pelo Brasil. Esse processo intensificou-se nos anos 1990 e, segundo os pesquisados (Ellery Mourão, 2006), o estudante formado no Brasil passou a ser reconhecido pelo grande "pragmatismo" e pelas "idéias inovadoras", sendo mais bem aceito no mercado de trabalho cabo-verdiano e guineense. Ressalto que o primeiro ministro de Cabo Verde é formado pela Fundação Getúlio Vargas em São Paulo. Essa opção pelo Brasil acabou por gerar um confronto com o que já estava posto, mesmo antes de terem saído: a insistência em pertencer a Portugal, representando uma forma de oposição ao que havia sido estabelecido pela ex-metrópole — um modo de rebelar-se contra um sistema de coisas já montadas (o sistema colonial que está nas mentes), revelando as estruturas tradicionais culturais que ligam, de forma diferenciada, esses países a Portugal.

Nisto reside a importância em refletir sobre a ressignificação das nacionalidades dos estudantes formados no Brasil: por esta questão estar relacionada diretamente com as diferenças que essas formações - seja no Brasil, em Portugal, em Cuba ou na antiga União Soviética - podem representar na construção de um projeto de nação e dos ideais da nacionalidade em Cabo Verde e em Guiné-Bissau. A formação superior em Portugal, por exemplo, dá-se no contexto dos ex-colonizadores, diferentemente do Brasil que, além de estar na posição de ex-colonizado, viveu problemas semelhantes quanto à miscigenação e, em relação a Cabo Verde, também quanto aos processos de "branqueamento" 10 .

\section{Cabo-verdianidade e africanidade}

No que diz respeito à construção das nacionalidades cabo-verdianas, ressalto a recorrência, nos relatos dos pesquisados, de um discurso que privilegia a

10. Ver Fernandes (1978); Da Matta (1981); Chauí (200I). 
forma de colonização portuguesa em Cabo Verde e as elites cabo-verdianas como fundamentais à compreensão da construção da identidade nacional em Cabo Verde. Eles afirmaram que a forma de ocupação e as estratégias usadas pelos portugueses e pelas elites cabo-verdianas - aliadas aos portugueses, no projeto colonial - distanciaram os cabo-verdianos de suas "raízes africanas" e os aproximaram mais da "cultura européia", possibilitando questionar se são africanos, atlânticos, europeus ou uma mistura de todos esses atributos. Em suas definiçōes sobre a "cabo-verdianidade", muitos elementos identitários são acionados e se relacionam, como "raça", língua, religião e nacionalidade.

Os relatos (Ellery Mourão, 2006) apontaram uma relação entre o processo de miscigenação e a formação de "hierarquias raciais" como causa de uma perda da "identidade africana" em Cabo Verde, tendo o fator segregacionista das ilhas como principal responsável por essa perda. Seria em razão de um corte profundo entre os africanos escravizados e o continente; de uma cisão com os laços de parentesco, étnicos, culturais, lingüísticos e religiosos, na visão de alguns entrevistados; originais ou mesmo tradicionais, que os africanos de diversos países do continente trazidos para Cabo Verde teriam perdido suas "identidades africanas". A visão de "identidade africana" contida em muitos dos relatos é essencialista, supõe pureza e originalidade, muitas vezes reproduzindo o discurso da assimilação (passividade) pelo lado oprimido. Nesse caso, considero que, como foram forçados a reprimir e a negar seus referenciais culturais $^{11}$ (valores e crenças), pela impossibilidade de expressá-los livremente, os africanos continentais, vivendo em Cabo Verde, ressignificaram ${ }^{12}$ a maneira de sentirem-se africanos e de identificarem-se com o continente. Isso reforçado por um intenso e violento processo de tentativa de aculturação dos nativos pelo colonizador, com a imposição da religião católica, com a língua oficial portuguesa e com a educação estandardizada, sem que fossem respeitadas as diferenças entre as mais diversas etnias e suas tradiçōes culturais (costumes e crenças).

Segundo Vale de Almeida (2004b), essa dupla identificação (africana e européia) foi reafirmada por parte da elite intelectual cabo-verdiana, influenciada pela intelectualidade portuguesa e pelos ideais da Claridade $^{13}$ que se valeu, em

11. O conceito de cultura, ainda que pautado no significado das ações, de acordo com Geertz (1978), é visto de forma não essencializada, assim como o sentido de tradições culturais (valores e crenças partilhados socialmente entre indivíduos e passados de geração para geração) é considerado não fixo e não homogêneo.

12. Ver Sahlins (1990).

13. O movimento Claridoso era de cunho nacionalista e tinha como referência a Europa. Os intelectuais adeptos propunham a afirmação da identidade européia cabo-verdiana, buscando valorizar positivamente os "mestiços" pela assimilação das características físicas (raciais) e sociais (modos) portuguesas. 
meados do século XX, de analogias com o caso brasileiro para pensar a "caboverdianidade" 14 . Da mesma forma que, no Brasil, a intelectualidade exerceu grande influência nas construçôes acerca da identidade nacional, os caboverdianos - intelectuais (autores citados) e sujeitos entrevistados - privilegiaram abordagens que falavam em assimilação, miscigenação e ambigüidades identitárias (Freyre, 2000).

Quanto a este ponto, considerei que era menos uma questão de analogia e mais uma possível transposição da matriz ideológica de Freyre, para explicar o caso cabo-verdiano, uma vez que a obra desse autor foi central para que os intelectuais portugueses e cabo-verdianos articulassem o conceito biológico de raça à formação da identidade, pautando seus argumentos na idéia de assimilação (Vale de Almeida, 2004b). Os adeptos do movimento Claridoso, sobretudo, buscavam o valor positivo dos mestiços pela assimilação aos modos portugueses, se tratando de processos de branqueamento, com influência marcadamente de Freyre e suas idéias sobre o Brasil (Freyre, 2000). Inspirados no pensamento do autor brasileiro, disseminavam a idéia de que os mestiços tenderiam para o lado de maior influência social; portanto, o lado europeu. Afirmavam ainda uma grande disposição das mulheres africanas em ser mães, isso para tratar do caráter sexuado e de gênero da miscigenação, considerando a maternidade precoce como mecanismo de adaptação, alegando assim que não era possível acusar as "raparigas" de "desordem sexual e moral" (Vale de Almeida, 2004b, p. 268-269).

Paralelamente ao movimento Claridoso, havia outra corrente de pensamento que tinha sua ancoragem nas lutas de libertação na África e buscava as raízes cabo-verdianas africanas. A atuação do partido e a relação com a Guiné-Bissau era o elo que ligava Cabo Verde ao continente africano e a sua própria história - inserido, se não geograficamente, simbólica e politicamente no continente —. Mas, com a cisão do PAIGC (Partido para a Independência de GuinéBissau e Cabo Verde), os países tomaram rumos opostos e independentes um do outro. Cabo Verde criou o PAICV (Partido para a Independência de Cabo Verde) e afastou-se ainda mais do continente, com suas elites voltadas para a Europa, visando interesses políticos e econômicos.

Após 1990, instituiu-se democraticamente um novo governo e o regime tornou-se pluripartidário (Koudawo, 2001). Com isso ocorreram algumas mudanças que iriam afetar diretamente a questão da identidade nacional em Cabo Verde. Em termos simbólicos, a mais importante delas, segundo os entrevistados, foi a alteração arbitrária na letra do hino nacional e nas cores da bandeira

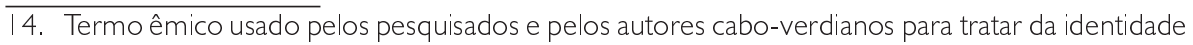
nacional. 
do país. Segundo relataram os pesquisados, as gerações que aprenderam o hino antigo e depois tiveram que aprender o novo, hoje se sentem "perdidas" pela falta de identificação com a nova letra do hino nacional e as novas cores da bandeira ${ }^{15}$. A recorrência aos símbolos nacionais, como o hino e a bandeira, na construção da identidade nacional de uma nação é algo criado para agregar os indivíduos em torno das mesmas representaçôes, dando unidade e, ao mesmo tempo, distinguindo uma nação das outras (Murilo de Carvalho, 1995). A mudança que houve em Cabo Verde ocorreu no intuito de afirmar a especificidade da identidade cabo-verdiana. E o argumento usado pelos governantes para essas alteraçôes nos símbolos nacionais, segundo os pesquisados, era de que a bandeira anterior remetia às cores da bandeira do PAIGC. Com a cisão entre os países, Cabo Verde deveria ter a sua própria bandeira e seu próprio hino, marcando a separação completa entre Cabo Verde e Guiné-Bissau como duas naçôes verdadeiramente distintas. Percebe-se, então, que ora se negou a "identidade africana", revelando forte influência portuguesa e européia, ora se afirmou, abraçando os ideais nacionalistas que foram construídos quando das lutas pela libertação nacional, em confronto com Portugal.

Conclui-se a persistência da influência portuguesa, mais acentuadamente em Cabo Verde, nas dimensões políticas, culturais, religiosas e econômicas. É nesse sentido que Ângelo Barbosa ${ }^{16}$ argumentou: "a nossa forma de funcionar aqui, em Cabo Verde, ainda em nível de organização do Estado e da estrutura mental das pessoas, tem as antenas parabólicas voltadas pra Lisboa, é preciso mudar o eixo".

Os relatos mostraram uma busca dos pesquisados pelo reconhecimento da parcela de identificação com o continente que foi sendo negada, indicando que a vivência no Brasil é também fator relevante para a tomada de consciência sobre a questão da "africanidade". Os deslocamentos possibilitam os trânsitos identitários, quando aproximam diferenças. Fora do país, diversos estudantes de nacionalidades diferentes passam a conviver cotidianamente uns com os outros, dividindo o mesmo espaço universitário, o que permite a eles um olhar para si e para o outro (Ellery Mourão, 2004). Em situação de deslocamento, como disse Anderson (1989), os indivíduos podem vivenciar um entendimento maior sobre si próprios e sobre os outros; sobre seu lugar de origem na rela-

15. Antes da cisão do partido, o hino era o mesmo para Cabo Verde e Guiné-Bissau, e a bandeira diferenciava-se apenas por alguns símbolos, mas mantinham as mesmas cores numa referência à Bandeira de Gana, primeiro país a obter a independência no continente africano. Agora as cores da nova bandeira teriam a predominância das cores branca e azul, com dez estrelas amarelas, numa referência à bandeira que simboliza os países europeus.

16. Ângelo Barbosa, cabo-verdiano, é administrador público, formado pela Fundação Getúlio Vargas em São Paulo. Ingressou em 1982 e terminou o curso em 1987, quando regressou para Cabo Verde. 
ção com outros lugares; sobre outras pessoas; e sobre outros referenciais culturais. Essa circunstância permite compararmos a nossa própria experiência com outra a nossa frente, diante da possibilidade de mudar, de ressignificar nossos valores, costumes, religião, língua, identidades e nacionalidades (Sahlins, 1990). É por isso que o trânsito vivenciado pelos estudantes africanos no Brasil se revela tão significativo.

O relato de Crisanto Barros ${ }^{17}$ em Ellery Mourão (2006, p.73) apresentou o processo de democratização e a formação de elites intelectuais como fatores importantes nessa busca pela história e pela reconstrução da identidade nacional.

Há uma reconstrução da identidade [...] A nossa identidade está numa dimensão plural, comporta várias dimensões. Há dimensōes que ficam mutiladas na história, mas eu creio que houve um resgatar com o processo de democratização e a força que a região Sul, Santiago, teve na formação das elites, porque são as elites que constroem os discursos que acabam sendo referenciais para a população. Houve um momento em que o nosso discurso foi um discurso voltado para um movimento de muita claridade, de que Cabo Verde é muito parecido com o Brasil. Mas no Brasil há Gilberto Freyre, um Brasil meio mulato meio moreno, né? A idéia é de que "Cabo Verde é um brasilinho", se dizia assim [...] Eu acho que o Brasil é um Cabo Verdão porque daqui foram as pessoas [...] Como no Brasil houve aquela política de branqueamento, de tornar mais branco, aqui houve também.

Percebe-se que Crisanto se remete às origens, assim como fizeram, sobretudo, os intelectuais do movimento Claridoso, mas o faz para refletir sobre o que foi ocultado da história de colonização e formação do Estado nacional, e com o intuito de pensar os processos de afirmação de identidades hoje. Isso leva a crer na formação de uma nova vertente de pensamento que aspira a reconstrução das identidades nacionais, mesclando todos os atributos que dela fazem parte. Essa vertente reconhece seu valor como elite intelectual em seu país, como sugere o relato de Crisanto, ao afirmar que são as elites que constroem os referenciais da população. Nesse sentido, questiono se ainda hoje o Brasil de Freyre continuaria representando uma possibilidade de reflexão para os intelectuais cabo-verdianos, quando eles dizem estar num processo de "reinvenção da cabo-verdianidade", pautada no processo histórico em todas as suas facetas,

17. Crisanto Barros, cabo-verdiano, é formado em Pedagogia na Universidade Fluminense (UFF). Na Universidade de Campinas fez graduação em Sociologia e mestrado em Educação (UNICAMP). Teve seu ingresso na universidade em 1991, regressando definitivamente para Cabo Verde em 1997. 
no que diz respeito não somente à história de Portugal, mas a uma história que fale da África, da escravidão, do racismo e das lutas de libertação nacional.

Cabo Verde é um país bastante ocidentalizado, com muitos carros importados, produtos de gêneros alimentícios, de vestuário, de mobiliário e de construção civil também importados, sobretudo de países da Europa, o que não é visto tanto no Brasil. Em Cabo Verde quase não se observam pessoas com trajes africanos: túnicas, panos na cabeça, roupas coloridas, crianças sendo carregadas em panos amarrados aos corpos de suas mães, como se observa em GuinéBissau. Um país bastante diferente de Guiné-Bissau e também do Brasil, Cabo Verde mostra ter ainda uma grande influência européia, marcadamente de Portugal, mas com influência também da África, pois é África. Um lugar particular, com indivíduos participantes de uma elite intelectual, que entendem Cabo Verde como uma nação não ocidental e sim africana, mas que carrega referenciais identitários tanto europeus como africanos, afirmando, assim, sua especificidade identitária e nacional. Nesse sentido, para entender o que os sujeitos reivindicam ao questionar o "peso da África na cultura cabo-verdiana", como argumentou a entrevistada Matilde Dias ${ }^{18}$, é preciso analisar todos esses fatores e elementos que fazem parte da realidade de Cabo Verde hoje. Essa atual elite intelectual diferencia-se da elite conservadora cabo-verdiana, volta seu olhar para o continente africano, mas também para si própria e para suas especificidades, buscando cada vez mais uma "independência" de Portugal, que ainda hoje exerce bastante influência sobre o país ${ }^{19}$. Buscam ainda a contínua valorização da educação, do conhecimento sobre a história da África, inserindo Cabo Verde nessa história, e o ensino do crioulo nas escolas (língua materna), como parte dessa mudança. Sobre o crioulo, é de autoria do Ministro da Cultura de Cabo Verde, Manuel Veiga, o projeto para instituição da língua como oficial, deixando o português como segunda língua. Tema ainda bastante discutido e gerador de polêmicas entre os cabo-verdianos, mas que marca uma afirmação da cabo-verdianidade e da singularidade de Cabo Verde como nação crioula, com suas múltiplas possibilidades de identificações que

18. Matilde Dias é cabo-verdiana formada pela Universidade Federal Fluminense (UFF) em Jornalismo. Ingressou em 1995, retornando ao seu país no ano 2000.

19. Segundo o entrevistado, o advogado cabo-verdiano Ulisses Santos, e dados publicados no site oficial do governo de Cabo Verde (www.governo.cv) todo o aparato jurídico do país se baseia no de Portugal, com uma e outra exceção. No plano econômico, Cabo Verde tem um acordo cambial com Portugal que sustenta a paridade fixa da moeda cabo-verdiana (escudo) com o euro ( I euro é igual a I I \$26). Nas privatizações que ocorreram no país desde a independência, a banca (conjunto de bancos que compõem o Sistema Financeiro Nacional) ficou majoritariamente nas mãos de bancos portugueses, bem como o setor de telecomunicações. O setor de energia e água, até o ano de 2006, também foi controlado pelos portugueses, e a maior parte das importações é feita no mercado português. 
não podem ser consideradas ambíguas, mas sim estratégicas e multifacetadas (Carneiro da Cunha, 1986).

\section{A Guiné-Bissau e o projeto de construção da nação guineense}

Se para os cabo-verdianos pesquisados os conflitos identitários ocorrem em razão de uma "perda" da identidade africana, na Guiné-Bissau as questôes são de outra ordem. Os pesquisados guineenses chamam a atenção para a diversidade étnica como ponto principal a ser observado quando se trata do tema das identidades. Hoje, na Guiné, os indivíduos diferenciam-se (marcando identidades) em indivíduos que se identificam como guineenses, referindo-se à nação e, ao mesmo tempo, a uma etnia específica, quando se referem ao grupo étnico ao qual pertencem, sem que uma identidade exclua a outra. Outros se identificam como "crioulos" guineenses, sem a identificação étnica, nesse caso excluída, uma vez que o crioulo remete à descendência cabo-verdiana agregada à nacionalidade guineense. Há ainda quem afirme sua nacionalidade como guineense, sem fazer referência a nenhuma etnia. Guiné-Bissau é composta tanto por guineenses pertencentes a diferentes etnias, crioulos guineenses (descendentes de cabo-verdianos nascidos na Guiné), como por senegaleses, árabes, nigerianos, libaneses, mauritanos, liberianos; enfim, não somente uma vasta diversidade étnica, mas também uma grande diversidade de identidades nacionais e lingüísticas.

O assunto mais urgente na Guiné-Bissau é a gestão dos conflitos étnicos no interior da política guineense - um processo denominado de "etnização da política”, que foi iniciado no período pós-independência pela formação de solidariedades políticas pautadas na questão racial, biológica, que estabeleceu diferenciaçôes hierárquicas entre as etnias da Guiné-Bissau. Os pesquisados afirmaram que antes, no período colonial, as etnias na Guiné-Bissau conviviam sem a existência de conflitos "visíveis"; cada regiāo tinha a predominância de uma determinada etnia e não havia problemas dessa ordem. As diferenças foram se acirrando aos poucos entre os grupos étnicos, que passaram a fazer uso do argumento da solidariedade racial para marcar diferenças e afirmar identidades. O processo, denominado de "balantização ${ }^{20 "}$, iniciou-se por parte de um membro da etnia balanta, Kumba Yalá, que para chegar ao poder fez sua campanha política presidencial, no ano de 1999, pautada na valorização de símbolos de sua etnia, Balanta, e no valor desta em detrimento das demais. Com isso, ele pretendia obter o apoio dos balantas para eleger-se presidente. Sua estratégia foi apoiada pelos balantas, que são majoritários em número na

20. Balantização é o termo usado para referir-se ao processo de diferenciação ocorrido hoje na Guiné-Bissau, iniciado pela etnia balanta, majoritária no país e nas Forças Armadas. 
Guiné-Bissau e também nas Forças Armadas. Após assumir a presidência levando o Partido da Renovação Social (PRS) ao poder até o golpe de Estado em 14 de setembro de 2003 -, Yalá adotou definitivamente a cor vermelha, símbolo dos balantas, na boina (ou quepe) que se tornou parte do fardamento dos militares.

Como foi relatado num artigo da revista África Lusófona ${ }^{21}$, esse processo vem se desenrolando com sérias conseqüências para a "unidade do país"; o jornalista redator José Sousa Dias afirmou que os militares guineenses "obedecendo a orientaçôes tribais [...] semeiam o terror e o medo no seio da população". Entender as particularidades desses processos torna-se bastante instigante num momento em que vários autores ditos pós-coloniais, como Edward Said, Stuart Hall, Homi Bhabha, Frantz Fanon, Antony Appiah, Stanley Tambiah, entre outros, falam de outro ângulo, não ocidental, desconstruindo, desnaturalizando e descentralizando o nosso olhar sobre as pesquisas realizadas por intelectuais ocidentais. Apresentam-nos um ponto de vista diferente, com grandes contribuições para o estudo das identidades, das mudanças culturais e dos estudos pós-coloniais. A nação moderna foi concebida para integrar os indivíduos por meio da construção de simbologias e ideais nacionalistas. Por meio do Estado, ela foi definida pela criação de fronteiras territoriais que possibilitassem distinguir e estabelecer limites entre os "Estados-Nação", mas isso no âmbito dos países ocidentais. Outras noções emergem pela força das mudanças culturais, contribuindo para o surgimento de diferentes maneiras de pensar a nação; uma idéia que parecia fixa pode vir a ser considerada relacional e não homogênea, dessa forma, definida a partir de uma situação empírica (Hall, 2003).

Antes da independência não havia a referência a uma identidade guineense; os indivíduos nascidos na Guiné-Bissau identificavam-se por uma identidade portuguesa, numa referência à Guiné portuguesa, em razão das políticas coloniais de incorporação dos nativos. Com a independência, os indivíduos passaram a afirmar uma identidade guineense, que no período colonial não lhes era permitida. Essa "identidade" é dada com a constituição do Estado nacional da Guiné-Bissau, legitimada pela lei e pelo direito, pautada no modelo ocidental de Estado-Nação. Este modelo pretende abarcar todas as diferenças num só rotulo: o da identidade nacional. Mas e quanto aos diferentes grupos étnicos da Guiné-Bissau? No período colonial, havia a obrigatoriedade de aceitar a identidade sobre a classificação de Guiné-Portuguesa - que negava suas identidades específicas como fulas, mandingas, balantas, papéis, dentre outras -, sem que eles pudessem se reconhecer e ser reconhecidos nem pela identidade étnica nem

21. Ver África Lusófona: política, economia e sociedade. Ano 3 - n²4 - novembro/dezembro, 2004, p.42-43. 
pela identidade portuguesa; assim, não se sentiam como parte de algo que os pudesse unir. De certa forma, se a eles restou apenas a alternativa de se reconhecerem como distintos de Portugal, unindo-se para a luta de libertação nacional e formação do Estado-Nação, é também porque não havia mais a possibilidade política de serem o que foram no passado. A eles restou uma única possibilidade: afirmar suas identidades em oposição à identidade portuguesa e, somente nessa situação, obter a união entre os indivíduos de todas as etnias e os caboverdianos, em nome da independência de Guiné-Bissau e Cabo Verde.

Segundo Stuart Hall (2003), a modernidade chegou com a força de destruir as tradiçôes, que foram vistas como obstáculos ao progresso. O ideal ocidental do "Estado-Nação" impôs fronteiras rígidas dentro das quais se esperava que as culturas florescessem: mesmo território, mesma língua, mesma religião, mesmas instituições. Essa foi a forma política construída pelos Estados soberanos no Ocidente, como também o referencial adotado pelas políticas nacionalistas para as novas naçóes africanas após a independência. Com a adoção do modelo ocidental na Guiné-Bissau e o conseqüente surgimento de conflitos entre as etnias, os líderes políticos guineenses passaram a questionar a força tradicional das etnias como um entrave para a democracia. A partir desse argumento, é possível observar a noção de tradição sendo empregada em oposição aos ideais de modernidade presentes no discurso dos governantes guineenses, explicitado pelos pesquisados em Ellery Mourão (2006). Então, de que maneira, à luz das formulaçōes mais recentes, poderemos refletir sobre como esse imaginário de que as diversas etnias dificultavam e/ou dificultam o progresso rumo à democracia guineense tem sido construído? Qual o conteúdo dessas construções ideológicas, como são formuladas e quais os seus usos para a obtenção de resultados políticos em contextos particulares? Da mesma forma que o fez Edward Said, na obra Orientalismo, seria possível considerar a idéia de África como uma construção do Ocidente? Segundo Said (2001), o Oriente foi classificado de acordo com o ideário ocidental. Esse processo não foi diferente do que ocorreu na África. Entretanto, cada situação tem suas especificidades. Os sentidos de nação e de modernidade dos países que foram colônias européias não são os mesmos que foram construídos no Ocidente, e esse é um dos pontos mais críticos para a ocorrência de conflitos étnicos e políticos na África. $\mathrm{O}$ guineense Veríssimo Paulino ${ }^{22}$ disse sobre esse assunto, em Ellery Mourão (2006, p.101):

Sabes que há algumas coisas que as pessoas ignoram [...] são as raízes culturais. Por mais que nós queiramos dizer que sou isento

22. Veríssimo Paulino é formado em Sociologia pela Universidade Federal de Santa Catarina. Ingressou na universidade em 1992. 
ou que estou um pouco ocidentalizado, tenho uma formação ocidental, existe sempre aquele toque cultural que é intrínseco a nós, que é a nossa lente, a nossa forma de ver o mundo. Nascemos e já aprendemos a ver o mundo com base nesses conceitos preestabelecidos, ou seja, preexistentes, e às vezes tentamos nos desprender destes princípios, destes conceitos, e acabamos sempre por cometer erros gravíssimos ao invés de tentarmos conciliar as coisas. A raiz cultural guineense é um obstáculo para democracia? Eu diria que sim e diria que não.

O relato de Veríssimo permite questionar a adoção do modelo do EstadoNação na Guiné-Bissau como uma estratégia de identidade no sentido de sobreviver a um mundo globalizado. Segundo Tambiah (1997), se considerarmos que muitos teóricos ocidentais e líderes políticos e intelectuais do Terceiro Mundo têm defendido a idéia do Estado-Nação como modelo sobre o qual se deve edificar a modernização e o desenvolvimento econômico, será importante atentar para duas coisas. Primeiro, não se pode esquecer que a concepção do Estado-Nação europeu foi resultado histórico de acontecimentos específicos da Europa. A segunda coisa é que a falta de governabilidade e desenvolvimento econômico em outros países não pode ser resolvida "usando" o Estado-Nação como uma fórmula para resolver esses problemas. Isso fez com que muitos teóricos, intelectuais e líderes políticos ocidentais e de países africanos incorressem no erro de tentar impor uma construção histórica ${ }^{23}$ como é o EstadoNação, concebido em território específico e distinto, a um mundo dependente, como se a constituição do Estado fosse uma etapa a ser cumprida universalmente. Tudo isto só poderá ser entendido se aliado à compreensão do colonialismo e pós-colonialismo em sua dimensão desestruturante, do ponto de vista étnico, considerando todos os interesses políticos e econômicos dos países dominantes no cenário global. Foi sob o impacto do modelo europeu sobre as formas e práticas sociais nas antigas colônias que os etnonacionalismos se tornaram evidentes. $\mathrm{O}$ autor ressalta ainda que as políticas de modernização, aliadas às políticas de educação e alfabetização, têm resultado em um aumento expressivo do número de pessoas letradas em populações que também crescem em ritmo explosivo, com a "emergência de uma juventude educada e semieducada que busca emprego em economias de crescimento lento que são incapazes de incorporá-las" (Tambiah, 1997, p.5). Esta juventude é o segmento mais ativo de movimentos etnonacionalistas.

Tambiah considera ainda que os princípios políticos da etnicidade são produto do entrelaçamento e também da oposição de dois processos globais: de um lado, o capitalismo mundial, operado pelas corporações multinacionais; e

23. Ver Hobsbawn (1998). 
do outro, a generalização do processo de construção das colônias libertadas, hoje governadas por elites intelectuais locais de diversas posiçôes, que precisam dar respostas a suas bases eleitorais também divididas e cujas opiniões políticas não são de modo algum unitárias e homogêneas. Os problemas de dependência das "novas naçôes", como os pesquisados relataram, desenrolam-se como uma "bola de neve". Assim como a Guiné-Bissau, Cabo Verde também necessita de ajuda externa, mas a situação é diferente. Desde a guerra civil de 1998, a Guiné-Bissau vive uma situação econômica difícil, em decorrência da corrupção, dos conflitos entre elites e etnias no poder (e no exército), que têm se envolvido intensamente nas questôes políticas, com os constantes golpes de Estado. É importante considerar a Guiné sob seus aspectos políticos e econômicos, mas, principalmente, culturais; aqueles aspectos que se referem às distintas identidades e estratégias identitárias construídas. Não é apenas uma questão de avaliar quem se inseriu melhor ou pior no modelo ocidental de Estado-Nação. Acredito que o maior desenvolvimento econômico de Cabo Verde em relação à Guiné-Bissau deve ser entendido também em termos dos interesses que os países colonizadores ou hegemônicos, no plano internacional, conferem a cada país em suas estratégias comerciais e de dominação tanto no período colonial, como no pós-colonial. Hoje, vale atentar que essas situaçôes diferenciadas dos países em relação aos processos globais privilegiam aqueles que estão mais bem situados no campo político e econômico, acentuando as desigualdades entre aqueles que historicamente ocupam posição marginalizada no cenário internacional, como é o caso das ex-colônias situadas no continente africano. Cabo Verde ocupa uma posição estratégica entre a Europa e a África, o que o beneficia em termos políticos e econômicos, embora também existam grandes desigualdades sociais no país. Contudo, tem conseguido converter a ajuda externa em melhores condiçôes para a população, consolidando relaçôes comerciais e de política externa com outros países. Constata-se que cada um participa de forma diferenciada nos processos globais; não se pode, portanto, abordar esses processos uniformemente. Mesmo entre os que estão em situação marginalizada, encontramos situaçôes diferentes. Guiné-Bissau em relação a Cabo Verde; Cabo Verde e Guiné-Bissau em relação ao Brasil; os três em relação à Europa, incluindo Portugal; e Portugal em relação à Europa como um todo.

Nesse sentido, os resultados da pesquisa de Ellery Mourão (2006) são especialmente relevantes num momento em que a política externa brasileira tem se voltado para a formação de alianças entre países que não ocupam posição hegemônica nos movimentos globais, destacando-se as ações do governo Lula em relação aos países africanos e sul-americanos. Dessa perspectiva, vale questionar se os convênios estudantis são iniciativas que promovem alianças que 
visam trazer benefícios iguais ou se apenas reforçam as desigualdades. Como disse um dos sujeitos da pesquisa, Ulisses, "não podemos esquecer que relações entre países são relaçôes de interesses". As alianças do atual governo brasileiro têm como um dos principais instrumentos as trocas bilaterais e a transferência de tecnologia e conhecimento entre o Brasil e esses países. Sabemos que essas trocas são feitas entre instituições, mas também entre indivíduos. Os estudantes cabo-verdianos e guineenses pesquisados dizem não pretender, com a formação, copiar modelos pré-concebidos, mas sim adaptar o conhecimento adquirido no Brasil a sua realidade. Para eles, a formação no Brasil é importante na medida em possibilita "ajudá-los a pensar", tendo em vista as diferenças entre os referenciais culturais, políticos e econômicos dos países. A magnitude dessa política está na construção de alianças (políticas, econômicas e culturais) e de relações de reciprocidade, como estratégias políticas no cenário internacional, que permitiram ao Brasil tornar-se um referencial de nação e de desenvolvimento para esses estudantes, possibilitando estreitar cada vez mais as relações entre os países da África de língua portuguesa e o Brasil.

\section{Referências bibliográficas}

ANDERSON, Benedict. Nação e consciência nacional. São Paulo: Ática, 1989.

APPIAH, Kwame Anthony. Na casa de meu pai: a África na filosofia da cultura. Rio de Janeiro: Contraponto, 1997.

BARNES, J.A. Redes sociais e processo político. In: FELDMAN-BIANCO, Bela (Org.). Antropologia das sociedades contemporâneas. Métodos. São Paulo: Global, 1987. p. 159-189.

BHABHA, Homi K. Interrogando a identidade: Frantz Fanon e a prerrogativa pós-colonial. In: O local da cultura. Belo Horizonte: Editora da UFMG, 1998.

CARNEIRO DA CUNHA, Manuela. Etnicidade: da cultura residual mas irredutível. In: Antropologia do Brasil: mito, história, etnicidade. São Paulo: Brasiliense; Editora da Universidade de São Paulo, 1986.

CARVALHO, José Murilo. A formação das almas: o imaginário da República no Brasil. São Paulo: Companhia das Letras, 1995.

CORREA E SILVA, António Leão. Combates pela história. Praia: Spleen, 2004.

CHAUI, Marilena. Brasil mito fundador e sociedade autoritária. 4. ed. São Paulo: Fundação Perseu Abramo, 2001.

DA MATTA, Roberto. Digressão: a fábula das três raças, ou o problema do racismo à brasileira. In: MATTA, Roberto da. Relativizando: uma introdução à Antropologia social. Rio de Janeiro: Vozes, 1981. p. 58-85.

ELLERY MOURĀO, Daniele. África “na pasajen": identidades e nacionalidades guineenses e cabo-verdianas. 2006. Dissertação (Mestrado) — Departamento de Pós-Graduação em Sociologia, Universidade Federal do Ceará, Fortaleza - CE. 
ELLERY MOURÃO, Daniele. Identidades em trânsito: um estudo sobre o cotidiano de estudantes guineenses e cabo-verdianos em Fortaleza. 2004. Monografia — Universidade Federal do Ceará, Fortaleza - CE. (Mimeo).

EVANS-PRITCHARD, E. E. Os nuer. São Paulo: Perspectiva, 1978.

FANON, Frantz. A Argélia se desvela. In: CORRÊA, Mariza (Org.). Ensaios sobre a África do Norte. n. 46. Campinas-SP, fevereiro de 2002.

FERNANDES, Florestan. A integração do negro na sociedade de classes. São Paulo: Ática, 1978. v.1.

FREYRE, Gilberto. Casa-grande \& senzala. 39. ed. Rio de Janeiro: Record, 2000.

GEERTZ, Clifford. Uma descrição densa: por uma teoria interpretativa da cultura. In: GEERTZ, Clifford. A interpretação das culturas. Rio de Janeiro: Zahar, 1978.

GEERTZ, Clifford. O mundo em pedaços: cultura e política no fim do século. In: GEERTZ, Clifford. Nova luz sobre a Antropologia. Rio de Janeiro: Zahar, 2000.

GUSMÃO, Neusa Maria Mendes de. Os filhos da África em Portugal: Antropologia, multicuturalidade e educação. Belo Horizonte: Autêntica, 2005.

HERNANDEZ, Leila Leite. Os filhos da terra do sol: a formação do Estado-Nação em Cabo Verde. São Paulo: Summus, 2002.

HALL, Stuart. Da diáspora: identidades e mediaçôes culturais. Organização e apresentação de Liv Sovik. Tradução de Adelaine La Guardia et alii. Belo Horizonte: UFMG; Brasília: Representação da UNESCO no Brasil, 2003.

HOBSBAWM, J. Eric. A nação como novidade: da revolução ao liberalismo. In: Naçôese nacionalismo desde 1780. São Paulo: Paz e Terra, 1998.

KOUDAWO, Fafali. Cabo Verde, Guiné-Bissau: da democracia revolucionária à democracia liberal. Bissau: Instituto Nacional de estudos e Pesquisa (INEP), 2001.

SAHLINS, Marshall. Ilhas de história. Rio de Janeiro: Zahar, 1990.

SAID, Edward W. Orientalismo: o Oriente como invenção do Ocidente. São Paulo: Companhia das Letras, 2001.

TAMBIAH, Stanley J. Conflito etnonacionalista e violência coletiva no sul da Ásia. Revista Brasileira de Ciências Sociais, v. 12, n. 34, p. 5-24, 1997.

THOMAZ, Omar Ribeiro. Ecos do Atlântico Sul: representaçôes sobre o terceiro império português. Rio de Janeiro: Editora UFRJ/Fapesp, 2002.

VALE DE ALMEIDA, Miguel. Crioulização e fantasmagoria. Anuário antropológico. Rio de Janeiro: Tempo Brasileiro, 2004 a. p. 33-49.

VALE DE ALMEIDA, Miguel. O projeto crioulo. Cabo Verde, colonialismo e crioulidade. In: VALE DE ALMEIDA, Miguel. Outros destinos: ensaios de antropologia e cidadania. Porto: Campo das Letras, 2004 b. p. 255-319.

Recebido em 15 de julho de 2008 e aprovado em 26 de setembro de 2008. 